\title{
Topicality and anaphoricity in Dutch scrambling
}

\author{
Gert-Jan Schoenmakers $^{1}$ (D) Marjolein Poortvliet ${ }^{2} \cdot$ Jeannette Schaeffer $^{3}$
}

Received: 3 June 2020 / Accepted: 17 April 2021 / Published online: 28 April 2021

(c) The Author(s) 2021

\begin{abstract}
Direct objects in Dutch can precede or follow adverbs, a phenomenon commonly referred to as scrambling. The linguistic literature agrees in its assumption that scrambling is regulated by the topicality and anaphoricity status of definite objects, but theories vary as to what kinds of objects exactly are predicted to scramble. This study reports experimental data from a sentence completion experiment with adult native speakers of Dutch, showing that topics are scrambled more often than foci, and that anaphoric objects are scrambled more often than non-anaphoric objects. However, while the data provide support for the assumption that topicality and anaphoricity play an important role in scrambling, they also indicate that the discourse status of the object in and of itself cannot explain the full scrambling variation.
\end{abstract}

Keywords Scrambling · Dutch · Topicality · Anaphoricity · Definite Objects

\section{Introduction}

Dutch is one of many languages that allows scrambling, a term coined by Ross (1967) referring to a reordering of constituents. In Dutch, one type of scrambling occurs in the middle-field of the clause and refers to the relative order of the direct object and the adverb (Vanden Wyngaerd 1989; Neeleman 1994; Neeleman and Reinhart 1998; Broekhuis 2008; Neeleman and van de Koot 2008). ${ }^{1}$ An example of a scrambling construction is given in (1). The object position that follows the adverb is referred to as the unscrambled position (as in (1a)), while the object position that precedes the adverb is called the scrambled position (as in (1b)).

\footnotetext{
${ }^{1}$ The scrambling literature traditionally revolves around the questions whether the two orders are basegenerated or derived by movement, and whether this type of scrambling involves $\mathrm{A}$ - or $\mathrm{A}^{\prime}$-positions. We will not discuss these questions in this paper, but instead focus on the extent to which different types of definite objects scramble.
}

\footnotetext{
$\triangle$ G.T. Schoenmakers g.schoenmakers@let.ru.nl

1 Radboud University, Nijmegen, the Netherlands

2 Charles University, Prague, Czechia

3 University of Amsterdam, Amsterdam, the Netherlands
} 
(1) a. dat Jan gisteren het boek las.

that Jan yesterday the book read

'... that Jan read the book yesterday.'

Unscrambled

b. dat Jan het boek gisteren las.

that Jan the book yesterday read

'... that Jan read the book yesterday.'

Scrambled

A question that has surfaced in the linguistic literature is whether sentences with a definite direct object in scrambled position and sentences with a definite object in unscrambled position can be used interchangeably in any context, and, if not, which factors influence the relative order of the definite object and the adverb. The literature offers diverging answers to these questions, all highlighting the role information structure plays. Thus, most accounts predict that the two structures in (1) cannot be used interchangeably in any context, rather, the choice depends on discourse or information packaging conditions.

The literature has reached a general consensus that the topicality and the anaphoricity (terms we will define in Sect. 2.1) of a definite object affect its placement relative to an adverb. Definites that are topical and/or anaphoric are predicted to appear in scrambled position, while non-anaphoric focused definites are predicted to appear in unscrambled position. But there is still disagreement about exactly which types of objects scramble, and about whether or not scrambling is an optional operation. Moreover, the analyses proposed in the literature are mostly based on intuitions of the researchers; experimental data are scarce. The purpose of this study is to experimentally investigate the claims about definite objects in the main bodies of literature by means of a sentence completion experiment. As such, the study aims to build a bridge between theoretical linguistics and psycholinguistics. Studies on Dutch scrambling that report experimental data so far have investigated the L1 and L2 acquisition of scrambling structures (Schaeffer 1997, 2000; Unsworth 2005), the referentiality of the object (de Swart and van Bergen 2011), and the role that different types of adverbs and negation play (Schaeffer 1997, 2000; Schoenmakers and de Swart 2019; Schoenmakers 2020). The influence of a definite object's topicality and anaphoricity has not yet been investigated experimentally, yet various linguistic theories make precise predictions regarding the scrambling behavior of definite objects that depend on these factors. The current paper addresses this issue by manipulating the topicality and anaphoricity of definite objects in Dutch scrambling clauses with a temporal adverb. The paper is organized as follows. Section 2 introduces our definitions of the information structural notions that we will use and discusses the main theoretical analyses in the literature on Dutch scrambling of definite objects. Section 3 presents our experimental design, followed by the results in Sect. 4 and a general discussion in Sect. 5. Section 6 contains the conclusions.

\section{Background}

Although the literature on Dutch scrambling agrees that scrambling is dependent on discourse, there is disagreement about the specific conditions that influence scrambling, and in particular, scrambling of definite objects. This section reviews the fol- 
lowing analyses on the interaction between Dutch scrambling and information structure:

i) Scrambling as an obligatory process for topics (Neeleman and Reinhart 1998);

ii) Scrambling as an obligatory process for anaphoric objects (Schaeffer 1997, 2000);

iii) Scrambling as an obligatory process for continuous topics (Erteschik-Shir 2007);

iv) Scrambling as a preferred (but not obligatory) process for anaphoric objects (de Hoop 2000, 2003);

v) Scrambling as an optional, but undesirable process for all objects (van Bergen and de Swart 2009; de Swart and van Bergen 2011).

Before discussing the literature, however, we must explain the terminology that we will use throughout the paper. This is done in Sect. 2.1.

\subsection{Terminology}

We refer to an entity as anaphoric if there is explicit mention of it in the preceding discourse. That is, anaphoric entities convey discourse-given information, whereas non-anaphoric entities convey discourse-new information. An example is given in (2). The man in (2b) is anaphoric, because he is already mentioned in (2a). The pronouns he and his in (2b) are anaphoric as well.

a. I spoke to a man and a woman yesterday.

b. The man is a dentist, and he really likes his job.

We must also clarify our usage of the notions of topic and focus in a sentence, especially because the literature on information structure is notoriously convoluted with alternative definitions for the same terms and, conversely, no agreed upon appellation for specific definitions (see de Swart and de Hoop 2000 for an overview). In this paper we will use the following definitions. Foci represent the informative or contrary-toexpectation part of the sentence (Vallduví 1992; Vallduví and Engdahl 1996), or, as Lambrecht (1994) puts it, they are the semantic component of a pragmatically structured proposition where the assertion differs from the presupposition. An example to illustrate this is given in (3), in which speaker A's question licenses flowers in speaker B's answer to be the sentence focus.

Speaker A: What did Mary buy?

Speaker B: Mary bought [flowers $]_{\text {FOC }}$.

It is important to note that even though foci are typically non-anaphoric, because the informative part of a clause is usually new to the discourse, this is not necessarily the case, as evidenced by the example in (4). Speaker A asks about who John's wife loves, which licenses John in speaker B's answer as the focus of the clause, even though he has been mentioned in discourse before. That is, John is an anaphoric (discourse-given) focus in (4).

(4) Speaker A: Who does John's wife love?

Speaker B: John's wife loves [John $]_{\text {FOC. }}$. 
The (sentence) topic, by contrast, is the entity that the proposition is about (Reinhart 1981; Gundel 1988; Lambrecht 1994). The topic of a sentence is the entity that the speaker intends to increase the addressee's knowledge about, request information about, or otherwise get the addressee to act with respect to (Gundel 1988). Topics in this sense are sometimes also referred to as part of the presupposition or background: information that is shared among interlocutors. Therefore, topics typically convey known information that the sentence comments on, although they can, as Chafe (1976:30) puts it, be present 'in the consciousness of the addressee at the time of the utterance' without having been mentioned explicitly in the discourse. That is, anaphoricity or givenness is not a necessary condition for topic-hood. ${ }^{2}$ de Swart and de Hoop (2000:115, their (23)) borrow the example in (5) from Vallduví (1992) to illustrate this. Although crack is the topic of the sentence it appears in, it is entirely new to the discourse.

(5) I can't find broccoli anywhere. Crack they sell at every corner, but broccoli it's like they don't grow it anymore.

Another example of a non-discourse related topic is a permanently available topic, the referent of which is universally known and understood. These elements often refer to the speaker, the addressee, or 'permanent and temporary fixtures of our world' (Erteschik-Shir 2007:18), that is, referential information that is always shared by the interlocutors. Examples of permanently available topics include the sun, the prime minister, and the king. Ariel (1990) argues that this type of encyclopedic knowledge is stored in long-term memory and is therefore immediately accessible to the interlocutors, and Lambrecht (1994) reasons that permanently available topics must always convey presupposed information. Consider the sentences in (6). Even if the Good Book in (6a) is not mentioned explicitly in the preceding context, language users can effortlessly identify the referent (the Bible) at the time of utterance, because it is permanently available in their consciousness. This is not the case for the thick book in (6b), which cannot be identified without additional context.

a. The Good Book says tattooing is a witchcraft rite.

b. The thick book was a gift from my mother.

Topics thus do not necessarily refer to explicitly mentioned referents in the discourse, but can sometimes be identified based on long-term shared information or world knowledge. Note also that the topicality of an element is related to, but does not depend on its grammatical position (Reinhart 1981; see also Vogels and van Bergen 2013). Although topics naturally occur in subject position, they can also occur in other positions.

The present study investigates different types of sentence topics and foci in object position, resulting from a manipulation of the cognitive accessibility (or "aboutness") of potential referents in the preceding discourse. Consider the short narratives in (7). In both examples, a bicycle is introduced into the discourse as a new referent, but the

\footnotetext{
${ }^{2}$ Reinhart's (1981) definition of topics diverges from that used in the Prague School (e.g. Sgall et al. 1986) on this point. According to her, not all topical information is anaphoric information. We follow her definition in this paper.
} 
cognitive accessibility of this referent at the end of the two sentences differs between (7a) and (7b). The example in (7a) starts out by stating that the narrative is about a bicycle, thereby activating the referent in discourse, and then continues to provide additional information about this bicycle, such as its color and the current status of its wheel. At the end of the two sentences in (7a), the referent of the noun fiets 'bicycle' is strongly activated, i.e. it is highly cognitively accessible. The narrative in (7b), by contrast, is about Sophie and continues to provide additional information about her. While the bicycle is introduced into the discourse as a new referent here as well, at the end of the narrative it is not as accessible as the referent of the noun fiets 'bicycle' in (7a). Simply put, example (7a) is about a bicycle, and example (7b) is about Sophie.

a. Dit gaat over een geleende fiets die Sophie heeft gesloopt. Het is een zwarte fiets met een flinke slag in het wiel.

'This is about a borrowed bicycle that Sophie wrecked. It is a black bicycle that has a buckled wheel.'

b. Dit gaat over Sophie die een geleende fiets heeft gesloopt. Ze maakt wel vaker per ongeluk andermans spullen stuk.

'This is about Sophie who wrecked a borrowed bicycle. She often breaks other people's things by accident.'

Consequently, the ease with which the referent of the noun fiets 'bicycle' is retrieved from working memory in later discourse (or, its cognitive accessibility) differs between (7a) and (7b). Both narratives can be continued by a sentence such as Sophie gaat de fiets repareren 'Sophie will repair the bicycle'. After (7a), de fiets 'the bicycle' serves as an (anaphoric) topic in this continuation clause, because the narrative is about the bicycle. The cognitive accessibility of the referent of fiets 'bicycle' is high and can easily be retrieved from working memory. The cognitive accessibility of this referent after ( $7 b)$, by contrast, is considerably lower. The referent of fiets 'bike' cannot play the role of sentence topic in the continuation clause after (7b), because the discourse is primarily about Sophie (that is, Sophie is the sentence topic). Instead, de fiets 'the bicycle' serves as an (anaphoric) focus in this continuation clause. Besides anaphoric topics and anaphoric foci, the current study also investigates non-anaphoric foci and (non-anaphoric) permanently available topics.

Now that we have explained our definitions of anaphoricity, topic, and focus, we turn to the literature on Dutch scrambling. The next sections discuss the main proposals on the interaction between scrambling and information structure. It is important to note that the syntactic position of an adverb may affect scrambling preferences. As different types of adverbs occupy different positions in syntactic structure (Cinque 1999), the position of a scrambled object is variable as well (Schaeffer 1997, 2000; Schoenmakers and de Swart 2019). The analyses we discuss in the upcoming subsections are, by default, concerned with clauses with a structurally high temporal adverb.

\subsection{Neeleman and Reinhart (1998)}

Neeleman and Reinhart (1998) provide an analysis of Dutch scrambling in terms of 'destressing.' It has long been known that the main stress of a clause correlates 
with focus identification. Since the main stress of a clause is assigned to its most deeply embedded constituent (Cinque's 1993 Nuclear Stress Rule), Neeleman and Reinhart argue that Dutch scrambling serves as a mechanism to avoid the assignment of stress (and therefore focus) to definite objects that are not supposed to be the focus. Although Neeleman and Reinhart initially discuss destressing as an anaphoric process, they later link the scrambled position to the topicality and accessibility of a discourse referent instead (in the sense of Ariel 1990; cf. D-linkedness in Pesetsky 1987). They assert that anaphoricity itself cannot sufficiently explain scrambling patterns; for instance, if an entity has been mentioned too far back in the discourse, it may not scramble. The scrambled position is consequently reserved for highly accessible referents, i.e. anaphoric topics, and the unscrambled position for non-anaphoric foci. Neeleman and Reinhart's (1998) analysis is not concerned with permanently available topics nor anaphoric foci.

Consider the dialogues in (8) and (9). The phrase het boek 'the book' is the focus in (8), and the topic in (9). ${ }^{3}$ Neeleman and Reinhart's (1998) analysis predicts that the scrambled answer in (8b) is disfavored compared to the unscrambled answer in (8a), because the (non-anaphoric) focused object does not surface in the position that is associated with foci. By contrast, the unscrambled variant in (9a) is disfavored compared to the scrambled variant in (9b), because the (anaphoric) topical object appears in a stressed position.

(8) Hoe zit het met de voorbereidingen van je examen?

how goes it with the preparations for your exam

'How are you progressing with your exam preparations?'

a. Ik ga morgen het boek lezen.

I go tomorrow the book read

b. \#Ik ga het boek morgen lezen.

I go the book tomorrow read

'I will read the book tomorrow.'

(9) Hoe zit het met je review van dat boek?

how goes it with your review of that book

'How are you progressing with your review of that book?'

a. \#Ik ga morgen het boek lezen.

I go tomorrow the book read

b. Ik ga het boek morgen lezen.

I go the book tomorrow read

'I will read the book tomorrow.'

Under Neeleman and Reinhart's (1998) view, scrambling is obligatorily driven by destressing and information structure: topical (accessible, anaphoric) definite objects must be in scrambled position in order to avoid stress assignment, whereas focused (non-anaphoric) definite objects must be in unscrambled position, where they can

\footnotetext{
${ }^{3}$ For the sake of simplicity, we took the liberty to refer to what Neeleman and Reinhart (1998) call 'semantically uninformative' elements as topical elements (see also Neeleman and van de Koot 2008).
} 
receive focal stress. ${ }^{4}$ The (simplified) linear order in scrambling clauses predicted by Neeleman and Reinhart is presented in (10). Anaphoric topics appear to the left of the adverb, and non-anaphoric foci appear to their right.

$$
\text { [topic][adverb][focus] }
$$

\subsection{Schaeffer $(1997,2000)$}

Schaeffer $(1997,2000)$ agrees with the claim in Neeleman and Reinhart (1998) that scrambling is an obligatory process triggered by discourse conditions, but argues that it is the anaphoricity of the definite object that determines its surface position. She distinguishes between anaphoric and non-anaphoric objects: anaphoric objects scramble, while non-anaphoric objects remain unscrambled. The main difference between the predictions of her account and Neeleman and Reinhart's can be illustrated by scrambling clauses with a permanently available topic. Since these topics are inherently accessible to the interlocutors, but not necessarily anaphoric, Schaeffer predicts that they do not scramble if they have not been explicitly mentioned in the discourse (but note that Neeleman and Reinhart do not discuss this type of topic). Consider the dialogues in (11) and (12). De zon 'the sun' in (11) is a permanently available topic that is not mentioned in the immediately preceding discourse. According to Schaeffer, it must therefore remain in unscrambled position, as in (11a), where it naturally receives the stress it needs by virtue of being the most embedded constituent in the sentence (Cinque's 1993 Nuclear Stress Rule). ${ }^{5}$ The topic de brochure 'the brochure' in (12), by contrast, is not a permanently available topic, but it is anaphoric and must therefore scramble.

(11) Waarom denk je dat Colette zo vroeg is opgestaan? why think you that Colette so early is woke.up 'Why do you think Colette got up so early?'

a. Ik denk dat ze vanmorgen de zon wilde zien opkomen.

I think that she this.morning the sun wanted see rise

b. \#Ik denk dat ze de zon vanmorgen wilde zien opkomen.

I think that she the sun this.morning wanted see rise

'I think that she wanted to see the sun rise this morning.'

(12) Wat zei je dat Saskia met de brochure gedaan heeft? what said you that Saskia with the brochure done has 'What did you say Saskia did with the brochure?'

a. \#Ik zei dat ze gisteren de brochure gelezen heeft.

I said that she yesterday the brochure read has

'I said that she read the brochure yesterday.'

\footnotetext{
${ }^{4}$ Information structural and stress properties are only indirectly associated. In this paper, we focus on information structure; for more extensive discussion on the relation between stress and (discourse) meaning we refer the reader to Beaver and Clark (2008) and Büring (2016).

${ }^{5}$ The sentence in (11b) would be acceptable if (emphatic) stress were added to de zon 'the sun', which would be an additional operation and therefore less economical than (11a), in which the required stress on de zon is obtained by default under the Nuclear Stress Rule (Cinque 1993). We acknowledge the possibility of alternative stress patterns but will not further discuss this in the rest of this paper.
} 
b. Ik zei dat ze de brochure gisteren gelezen heeft.

I said that she the brochure yesterday read has

'I said that she read the brochure yesterday.'

The linear order of definite objects and adverbs as predicted by Schaeffer (1997, 2000) is given in (13). Anaphoric definite objects (including anaphoric permanently available topics) must appear in scrambled position, while non-anaphoric definite objects (including non-anaphoric permanently available topics) must appear in unscrambled position. It is important to note here, however, that Schaeffer $(1997,2000)$ does not specifically discuss anaphoric foci.

[object $\left._{\text {anaphoric }}\right]\left[\right.$ adverb] [object $\left.{ }_{\text {non-anaphoric }}\right]$

\subsection{Erteschik-Shir (2007)}

Erteschik-Shir's (2007) account is in line with Schaeffer's (1997, 2000) proposal in that non-anaphoric objects must appear in unscrambled position. However, ErteschikShir proposes that an additional distinction between continuous topics and shifted topics better explains the scrambling data. Shifted topics are topics that served as the focus in the preceding sentence(s), but serve as a topic in the current dialogue. Continuous topics, by contrast, were already topical in the previous sentence(s) and simply extend their topicality status. Erteschik-Shir reasons that, unlike continuous topics, shifted topics seem to be tolerated in the scope of negation. Consider the dialogues in (14) and (15). These examples show scrambling structures with a topic shift (from dierentuin 'zoo' to museum 'museum') and a temporal adverb (14) or negation (15). Erteschik-Shir claims that there is a contrast between these two structures. Both word orders are fully grammatical if the adverb is a temporal adverb (14), although the scrambled variant is the marked option. Negation, on the other hand, is 'associated with focus' (Jackendoff 1972), and its scope domain consequently cannot contain a topic. This renders the unscrambled position for the object in (15a) infelicitous for the given context. Erteschik-Shir concludes that definite objects must be placed in scrambled position when the sentence contains negation (but see Schoenmakers and de Swart 2019; Schoenmakers 2020).

(14) Toen ik op vakantie ging, raadde Johan mij het museum en de dierentuin aan. Ik ben meteen naar de dierentuin gegaan, waar ik urenlang heb rondgelopen. De dierentuin was inderdaad geweldig.

'When I went on vacation, Johan recommended the museum and the zoo. I went straight to the zoo, where I spent hours walking around. The zoo was amazing, indeed.'

a. Ik heb gisteren het museum bezocht.

I have yesterday the museum visited

b. \#Ik heb het museum gisteren bezocht.

I have the museum yesterday visited

'I visited the museum yesterday.'

(15) Toen ik op vakantie ging, raadde Johan mij het museum en de dierentuin aan. Ik ben meteen naar de dierentuin gegaan, waar ik urenlang heb rondgelopen. 
De dierentuin was inderdaad geweldig.

'When I went on vacation, Johan recommended the museum and the zoo. I went straight to the zoo, where I spent hours walking around. The zoo was amazing, indeed.'

a. *Ik heb niet het museum bezocht.

I have not the museum visited

b. Ik heb het museum niet bezocht.

I have the museum not visited

'I haven't visited the museum.'

Erteschik-Shir (2007) concludes that shifted topics are licensed in a position below the adverb, but above negation, and argues that scrambling should be analyzed in a broader context of constituent reordering. She claims that the reordering of shifted topics in many Germanic languages, including Dutch, is caused by topicalizationnot by scrambling. This proposal leaves scrambling to apply to continuous topics only.

Erteschik-Shir (2007) does not specifically address the scrambling behavior of anaphoric foci, or how exactly they can be distinguished from shifted topics, as there is an antecedent in the preceding discourse in both cases. Using the well-known file card metaphor (see Reinhart 1981; Vallduví 1992; Erteschik-Shir 1997), however, she claims that foci can 'locate an existing card and put it on the top of the file' (Erteschik-Shir 2007:44), which suggests that foci can sometimes be anaphoric. Erteschik-Shir (2007:144) also claims that '[t]he motivation for scrambling across an adverb [...] seems to be to remove the topic from the focused VP domain', which implies that foci must remain in unscrambled position, regardless of their anaphoricity.

Erteschik-Shir's (2007) analysis thus predicts that only continuous topics appear in (true) scrambled position (to the left of a temporal adverb); shifted topics, permanently available topics, and foci are all predicted to appear to the right of a temporal adverb. The linear ordering of topics and adverbs as predicted by Erteschik-Shir is illustrated in (16).

[topic continuous $_{\text {[ }}$ [adverb] [topic shifted/non-anaphoric $_{\text {[negation] [focus] }}$

\subsection{De Hoop $(2000,2003)$}

De Hoop (2000, 2003) provides an analysis of the interaction between discourse and scrambling that is slightly different from the previously discussed analyses. Instead of assuming that direct object scrambling is an obligatory process, de Hoop presents an Optimality Theoretic (OT) analysis, in which constraints may be violated, making the model's predictions less categorical. Although the analysis still predicts the syntactic behavior of direct objects on the basis of their definiteness and anaphoricity, it does not completely rule out unexpected form-meaning pairs. She proposes the following constraints, of which (17b) and (17c) are revised from Choi (1996). 
Table 1 Constraint tableau for anaphoric definite objects

\begin{tabular}{lllll}
\hline Input & Output & SC1 & NEW & CN2 \\
\hline Anaphoric definite & - scrambling & $*$ & $*$ & \\
Anaphoric definite & + scrambling & & & $*$ \\
\hline
\end{tabular}

Table 2 Results of possible rankings for anaphoric definite objects

\begin{tabular}{lll}
\hline Order & Output & Result \\
\hline$S C 1>N E W>C N 2$ & + scrambling & Anaphoric definites scramble in $2 / 3$ of the cases \\
$S C 1>C N 2>N E W$ & + scrambling & \\
$N E W>S C 1>C N 2$ & + scrambling & \\
$N E W>C N 2>S C 1$ & + scrambling & \\
$C N 2>S C 1>N E W$ & - scrambling & Anaphoric definites do not scramble in $1 / 3$ of the cases \\
$C N 2>N E W>S C 1$ & - scrambling & \\
\hline
\end{tabular}

Table 3 Constraint tableau for non-anaphoric definite objects

\begin{tabular}{lllll}
\hline Input & Output & SC1 & NEW & CN2 \\
\hline Non-anaphoric object & - scrambling & $*$ & & \\
Non-anaphoric object & + scrambling & & $*$ \\
\hline
\end{tabular}
a. $\quad$ Surface Correspondence (SC1):
Definite objects scramble.
b. New:
Anaphoric objects scramble.
c. Canonical Order (CN2):
Favor unscrambled word order.

Assuming that the constraints are not ranked with respect to each other, de Hoop $(2000,2003)$ proposes the OT tableau in Table 1. An anaphoric definite in unscrambled position violates the constraints $\mathrm{SC}$, because definites should scramble, and NEW, because anaphoric objects should scramble. Anaphoric definites in scrambled position only violate $\mathrm{CN} 2$, because the unscrambled word order is not used.

The possible rankings of constraints are presented in Table 2, as well as the corresponding predicted word order for clauses with an anaphoric definite. De Hoop (2000, 2003) follows Anttila and Cho (1998) in relating optionality to statistical preference: 'If a candidate wins in $n$ tableaux and $t$ is the total number of tableaux, then the candidate's probability of occurrences is $n / t$ ' (de Hoop 2000:164). Anaphoric definites are therefore predicted to occur in scrambled position in two out of three cases and in unscrambled position in one out of three cases (see Table 2).

De Hoop $(2000 ; 2003)$ performs a similar OT analysis for non-anaphoric definites, the constraint tableau of which is given in Table 3 . The violations are the same as for anaphoric definites in Table 1, except that the constraint NEW is not violated, because this constraint targets anaphoric objects only.

The possible constraint orders and predicted results are presented in Table 4. The analysis predicts that non-anaphoric definites occur in scrambled position in half of the cases. 
Table 4 Results of possible rankings for non-anaphoric definite direct objects

\begin{tabular}{lll}
\hline Order & Output & Result \\
\hline$S C 1>N E W>C N 2$ & + scrambling & Non-anaphoric definites scramble in $1 / 2$ of the cases \\
$S C 1>C N 2>N E W$ & + scrambling & \\
$N E W>S C 1>C N 2$ & + scrambling & \\
$N E W>C N 2>S C 1$ & - scrambling & Non-anaphoric definites do not scramble in $1 / 2$ of the cases \\
$C N 2>S C 1>N E W$ & - scrambling & \\
$C N 2>N E W>S C 1$ & - scrambling & \\
\hline
\end{tabular}

All in all, de Hoop (2000, 2003) argues that scrambling is an optional process, and predicts a probability of $2 / 3$ for anaphoric objects and a $1 / 2$ probability for nonanaphoric objects to occur in scrambled position. The linear ordering of definite objects and adverbs according to de Hoop can be presented as in (18) and (19).
a. [object anaphoric $_{\text {[ }}[$ adverb] $2 / 3$ chance
b. [adverb] [object anaphoric $_{\text {a }} 1 / 3$ chance
a. [object $t_{\text {non-anaphoric }}$ [adverb] $1 / 2$ chance

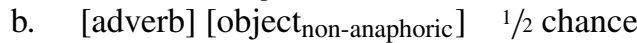

\subsection{Van Bergen and de Swart (2009); de Swart and van Bergen (2011)}

Van Bergen and de Swart (2009) conduct a corpus study in which they investigate (among other things) the role of the object's anaphoricity in scrambling structures. Their results show that even though anaphoric definites occur in scrambled position more often than non-anaphoric definites, only $22 \%$ of anaphoric definites do. In fact, van Bergen and de Swart report that only $8 \%$ of all objects with a definite article in their dataset are in scrambled position. This finding is unexpected considering the accounts discussed above.

De Swart and van Bergen (2011) present an experimental follow-up study in which they manipulate the anaphoricity of definite objects in scrambling clauses. The experiment took the form of a sentence completion experiment with 24 stimulus items consisting of an introduction and an intermediate sentence in one of two possible conditions (anaphoric or non-anaphoric). These lead-in sentences are followed by the beginning of the target sentence (an adverbial expression followed by the auxiliary heeft 'has') and four constituents: a nominative pronoun that matches the subject of the introduction sentences in person and gender, an infinitival transitive verb, a temporal adverb, and a definite noun phrase. A sample item is given in (20). Additionally, 46 filler items are added to the design. 40 participants were invited to a computer lab to (silently) read the lead-in sentences from a computer screen. The participants were instructed to construct a well-formed sentence making use of the constituents on the screen and to read the target sentence out loud. The utterances were recorded for later transcription. 


\section{Introduction sentence (same for both conditions):}

Christel had vorige week veel haast om thuis te komen.

'Last week Christel was in a hurry to get home.'

\section{Intermediate sentence:}

Op de ringweg kreeg ze een bekeuring voor hardrijden.

(anaphoric condition)

'On the ring road she got a ticket for speeding.'

Or:

Op de ringweg werd ze bij een stoplicht geflitst. (non-anaphoric condition) 'On the ring road she got caught running a red light.'

\section{Target sentence (same for both conditions):}

Zonder protest heeft zij \{de bekeuring\} meteen \{de bekeuring\} betaald.

'Without complaining she immediately paid the ticket.'

De Swart and van Bergen (2011) observe an overall preference for the unscrambled order in their data, a finding that is in line with their previous corpus study. More importantly for the purposes of our study, de Swart and van Bergen find that, although anaphoric objects occurred in scrambled position more often than non-anaphoric objects (14\% vs. $8 \%$, respectively, in the ADV > OBJ order of presentation; $34 \%$ vs. $33 \%$ in the OBJ $>$ ADV order of presentation), this effect did not reach significance. They conclude that ' $[\mathrm{t}$ ] ogether with the findings in van Bergen and de Swart (2009) these results strongly suggest that anaphoricity has hardly any effect on scrambling in Dutch,' and that '[t]hese findings contradict assumptions about the influence of this factor generally made in the theoretical literature' (de Swart and van Bergen 2011:16).

However, the authors note that the non-anaphoric definites in their experiment may have been inferred implicitly by virtue of the given context. For instance, the fact that Christel in (19) got caught running a red light in the non-anaphoric condition strongly implies that she got a ticket. This implication may have activated the noun ticket in discourse regardless of whether or not it is overtly expressed (bridging in Clark 1975 and Asher and Lascarides 1998). A putative effect of anaphoricity may have been obscured in de Swart and van Bergen's (2011) experiment because of the stimulus objects' overall salience in discourse. Be that as it may, the data from the corpus study and the experimental study strongly suggest that scrambling is not obligatory for Dutch definites, even if they are anaphoric.

\subsection{Predictions}

We have established that various analyses of definite object scrambling in Dutch have been put forward in the literature that consider the topicality and anaphoricity of the object. Yet, exactly which objects are predicted to scramble differs across the analyses. Table 5 schematically shows the predictions from the analyses we discussed in this section. ${ }^{6}$

\footnotetext{
${ }^{6}$ Neeleman and Reinhart (1998) do not discuss permanently available topics or anaphoric foci. Under their analysis, permanently available topics are either focused or topical depending on the context and
} 
Table 5 Overview of elements that are predicted to scramble according to different analyses, where + represents 'scrambled', - represents 'unscrambled', and $2 / 3$ and $1 / 2$ stand for the predicted proportions of scrambled/unscrambled instances

\begin{tabular}{lllll}
\hline & $\begin{array}{l}\text { Anaphoric } \\
\text { topics }\end{array}$ & $\begin{array}{l}\text { Anaphoric } \\
\text { foci }\end{array}$ & $\begin{array}{l}\text { Permanently } \\
\text { available topics }\end{array}$ & $\begin{array}{l}\text { Non-anaphoric } \\
\text { foci }\end{array}$ \\
\hline Neeleman and Reinhart (1998) & + & NA & NA & - \\
Schaeffer (1997, 2000) & + & + & + (anaphoric) & - \\
Erteschik-Shir (2007) & + & - & - & - \\
De Hoop (2000, 2003) & $2 / 3$ & $2 / 3$ & $1 / 2$ & $1 / 2$ \\
Van Bergen and de Swart & - & - & - & - \\
$(2009) ;$ de Swart and van Bergen & & & & \\
$(2011)$ & & & & \\
\hline
\end{tabular}

Neeleman and Reinhart's (1998) account predicts that anaphoric topics scramble, whereas non-anaphoric foci do not. Their analysis does not make any predictions regarding permanently available topics or anaphoric foci. Schaeffer's (1997, 2000) account predicts that all anaphoric objects must scramble (regardless of their topicality); non-anaphoric objects are predicted not to scramble. Erteschik-Shir's (2007) account predicts that only continuous topics scramble; permanently available topics, shifted topics, and foci (anaphoric or non-anaphoric) are predicted not to scramble. De Hoop $(2000,2003)$ submits that while there are preferences in scrambling that are informed by discourse, there is no one-to-one relationship between an object's surface position and its discourse status. Her analysis predicts that two out of three anaphoric objects and half of the non-anaphoric objects appear in scrambled position. Finally, the corpus and behavioral data in van Bergen and de Swart (2009) and de Swart and van Bergen (2011) suggest that there is a distinct preference for all definite direct objects to appear in unscrambled position, regardless of their discourse status.

The next section reports on a sentence completion experiment to test the predictions from these accounts. Specifically, we test whether:

i) anaphoric objects (topics and foci) occur in scrambled position more often than in unscrambled position;

ii) non-anaphoric objects (permanently available topics and discourse-new foci) occur in unscrambled position more often than in scrambled position;

iii) anaphoric objects are scrambled more often than non-anaphoric objects;

iv) topics are scrambled more often than foci.

The accounts in Table 5 not only make diverging claims on the exact nature of the discourse conditions that influence scrambling, they also disagree about whether

stress pattern. We thank an anonymous reviewer for pointing this out to us. Similarly, Schaeffer (1997, 2000) does not discuss anaphoric foci in her analysis. Given that she attributes the scrambling variation to anaphoricity effects, however, we marked her prediction for anaphoric foci as ' + ' in Table 5. Finally, de Hoop $(2000,2003)$ does not include permanently available topics in her model. According to her, however, permanently available topics can never be anaphoric and therefore scrambling of such definites is "completely optional" (de Hoop 2000:157-158). 
scrambling is obligatory (Neeleman and Reinhart 1998; Schaeffer 1997, 2000; Erteschik-Shir 2007) or optional (de Hoop 2000, 2003; van Bergen and de Swart 2009; de Swart and van Bergen 2011). Providing production data from scrambling clauses with a definite object and a temporal adverb, our experiment also addresses the question as to whether scrambling is obligatory or optional.

\section{Methods}

We have established that the predictions emerging from the literature on Dutch scrambling differ with respect to the influence of the definite object's topicality and anaphoricity status on scrambling. This section describes a sentence completion experiment in which we manipulate the topicality and anaphoricity of definite objects to test which of the analyses best predicts the objects' scrambling behavior in language production.

\subsection{Participants}

44 adult native speakers of Dutch (32 female; mean age 24.5; age range 17-57; SD 6.6) were recruited from the SONA participant pool of Radboud University in Nijmegen to take part in a sentence completion experiment. Participants received partial course credit or a gift voucher of five euros for their participation. Data from two participants were discarded due to technical error, resulting in a dataset with data from a total of 42 participants.

\subsection{Materials}

We developed a novel sentence completion experiment in which participants are asked a) to read three-sentence preambles out loud from a computer screen, designed to determine the topicality and anaphoricity of the direct object in the target sentence, and b) to orally complete a sentence using three constituents (a transitive verb, a definite object, and a temporal adverb).

The experiment consists of two distinct sets of experimental conditions and a set of filler items. Regarding the two sets of experimental conditions, we are interested in the scrambling behavior of topics and foci, as defined and exemplified in Sect. 2.1, and in the influence of anaphoricity. However, while we are able to compare minimal pairs of target sentences with an anaphoric topic and an anaphoric focus such as those in (21), this is not possible for permanently available topics. Permanently available topics belong to a fixed set of lexical items, which, by definition, are permanently available to the mind of the language user. At no point are they ever non-topical while still referring to the same referent, hence these items cannot ever serve as foci in a minimal pair such as that in (21). For this reason, we distributed the stimuli over two sets of items: one set with anaphoric topics and anaphoric foci (henceforth the $\mathrm{T} / \mathrm{F}$ item set), and one set with permanently available topics (henceforth the PA item set). Each experimental set includes a context-free condition, which in the T/F item set served as a non-anaphoric focus condition (21c), and in the PA item set as a 
context-free baseline condition (22b). The PA item set thus tests for the scrambling behavior of permanently available topics, and for an effect of the general presence of linguistic context. Taken together, the experiment includes a total of five experimental conditions, sample items of which are provided in (21) and (22). The preamble of each condition ends with a variant of the question Wat gaat er gebeuren? 'What will happen?'. We discuss the separate conditions in more detail below.

\section{a. $\quad$ T/F Set - A: Anaphoric topic condition}

Dit gaat over een geleende fiets die Sophie heeft gesloopt. Het is een zwarte fiets met een flinke slag in het wiel. Wat gaat er gebeuren met de fiets?

'This is about a borrowed bicycle that Sophie wrecked. It is a black bicycle that has a buckled wheel. What will happen with the bicycle?'

b. T/F Set - B: Anaphoric focus condition

Dit gaat over Sophie die een geleende fiets heeft gesloopt. Ze maakt wel vaker per ongeluk andermans spullen stuk. Wat gaat Sophie doen?

'This is about Sophie who wrecked a borrowed bicycle. She often breaks other people's things by accident. What will Sophie do?'

c. T/F Set - C: Non-anaphoric focus condition

Wat gaat er gebeuren?

'What will happen?'

Target sentence: Sophie gaat (de fiets) gauw (de fiets) repareren. Sophie goes the bicycle soon repair

a. PA Set - D: Permanently available topic condition with context

Dit gaat over Jasper die een afspraak heeft met een speciaal iemand.

Hij kijkt er al heel erg lang naar uit. Wat gaat er gebeuren?

'This is about Jasper who has an appointment with a special someone. He has been looking forward to it for a long time. What will happen?'

b. PA Set - C: Permanently available topic condition without context Wat gaat er gebeuren?

'What will happen?'

Target sentence: Jasper gaat (de koning) weldra (de koning) ontmoeten. Jasper goes the king soon meet

Table 6 presents an overview of each experimental condition in terms of the topicality and anaphoricity of the object in the target sentence. The T/F item set contains 24 experimental items in three conditions. The PA item set contains eight experimental items in two conditions.

Let us first discuss the items in the $\mathrm{T} / \mathrm{F}$ item set. The topicality of the objects in this item set was manipulated according to a fixed formula. The preamble in condition A (anaphoric topic) mentions the target object three times, clearly marking it as the topic of the target sentence. The preamble in (21a), for example, introduces the referent fiets 'bicycle' into the discourse and continues to provide additional information about it, such as its color and the current status of its wheel, before asking what will happen with the bicycle. Since the discourse is predominantly about the bicycle, it licenses the bicycle as a topic in the sentence to be elicited. In contrast, the 
Table 6 Overview of the discourse status conditions in terms of topicality and anaphoricity

\begin{tabular}{lllll}
\hline Item set & Conditions & Example & Topical & Anaphoric \\
\hline $\mathrm{T} / \mathrm{F}$ & A. Anaphoric topic & $(21 \mathrm{a})$ & + & + \\
$(\mathrm{N}=24)$ & B. Anaphoric focus & $(21 \mathrm{~b})$ & - & + \\
& C. Non-anaphoric focus & $(21 \mathrm{c})$ & - & - \\
& & & & - \\
$\mathrm{PA}$ & D. with context & $(22 \mathrm{a})$ & + & - \\
$(\mathrm{N}=8)$ & E. without context & $(22 \mathrm{~b})$ & + & - \\
\hline
\end{tabular}

preamble in condition B (anaphoric focus) mentions the target object only once. The preamble in (21b) introduces a bicycle into the discourse in the first sentence, but the remainder of the preamble generally revolves around Sophie instead, before asking what Sophie will do. The eventual question thus licenses an information structural partitioning in which Sophie is the topic of the sentence to be elicited, while the bicycle is focused. ${ }^{7}$ Condition $\mathrm{C}$ (non-anaphoric focus) is an experimental condition which is presented free of context, as in (21c), only posing the question Wat gaat er gebeuren? 'What will happen?'. The bicycle is not mentioned at all in the preamble, which licenses the target object as a non-anaphoric focus in the sentence to be elicited.

Let us now turn to the PA item set. Target sentences in this item set contain a permanently available topic, such as de koning 'the king' in (22), instead of a regular noun. The PA item set is comprised of two experimental conditions: a condition D with context (22a) and a condition E without context (22b). Target objects in both conditions are topical by virtue of the permanent availability of the discourse referents. Target sentences in condition $\mathrm{D}$ are again preceded by a threesentence preamble in which the referent of the target object is not explicitly mentioned, see (22a). In contrast, target sentences in condition $\mathrm{E}$ are presented free of context, only posing the question Wat gaat er gebeuren? 'What will happen?', see (22b). Target objects are therefore non-anaphoric in both conditions. This way, we can disambiguate between a putative effect of anaphoricity and an overall effect of the presence of linguistic context in a comparison with the results from the T/F item set.

All target sentences consist of an introductory phrase, or a prompt, which contains a subject (proper name) and the verb gaat 'will' (lit. 'goes'), see (21) and (22). This prompt is followed by three constituents with which the participant must com-

\footnotetext{
${ }^{7}$ On the view that topics are cognitively activated and predictable elements that are available for quick retrieval from working memory (accessible in Ariel 1990), one could alternatively analyze the bicycle in (21b) as a shifted topic (see Erteschik-Shir 2007) instead of an anaphoric focus, given that it is not clear how long a discourse referent remains activated in the mental representation of the listener. For many grammatical phenomena it has been shown that topicality is not a notion that extends over long stretches of discourse indiscriminately (but see Marslen-Wilson et al. 1982; Ariel 1990:17-20). Whether we refer to these entities as anaphoric foci or as shifted topics does not affect any of the predictions in Table 5: none of the theories differentiate between shifted topics and anaphoric foci in terms of their scrambling behavior. We therefore maintain the term anaphoric foci throughout.
} 
plete the sentence: an infinitival transitive verb, a definite noun phrase, and a temporal adverb. Note that target objects are presented together with the definite article. While there is a general preference to refer to topical elements with pronouns (e.g. Givón 1983; Ariel 1990), in this paper we are interested in the scrambling behavior of definite noun phrases. The experiment is therefore designed in such a way that participants are encouraged to use a definite noun phrase in their responses, so as to avoid the potential preference for a pronoun. This design was also chosen to reduce the number of responses with an indefinite object, as such responses are irrelevant for the purposes of this study. Objects and adverbs are matched for length in syllables to avoid effects of grammatical weight. In order to control for possible effects of structural priming, we included the order of presentation of constituents in the experimental design, referring to the relative vertical order of the object and the adverb when the stimulus material is presented on the screen. Half of the items are presented in the ADV > OBJ order; the other half are presented in the $\mathrm{OBJ}>\mathrm{ADV}$ order. The verb is presented above or below the adverb and object, or in between the two, and is presented in each position in an equal number of trials.

Finally, we created 48 filler items that exclusively elicit structures irrelevant to scrambling. The three constituents in the filler items are infinitival transitive or ditransitive verbs with (two of) their arguments. Note that there is little to no freedom in the word order of the elicited filler sentences. Examples are provided in (23) through (26). Half of the filler items are presented free of context so as to mimic the contextfree experimental items; these introduced the question Wat gaat er gebeuren? 'What will happen?' with or without an adverbial expression, see (23) and (24), respectively. The adverbial expressions are added to half of the filler items to make it more difficult for participants to identify the target items. In case the filler item contains an adverbial expression, the adverbial expression is the first constituent in the target sentence prompt. The other half of the filler items contain a three-sentence preamble, so as to mimic the non-context-free experimental items, see (25) and (26). The introductory phrase of the target sentence either repeats the adjunct of the preamble, as in (25), or has a DP in first sentence position, as in (26).

\section{Context-free fillers}

Wat gaat er gebeuren?

'What will happen?'

Intended answer: De professor gaat de promovendus de theorie bijbrengen. the professor goes the Ph.D.-student the theory teach 'The professor will teach the Ph.D. student the theory.'

Wat gaat er gebeuren na enige onrust?

'What will happen after some clamor?'

Intended answer: Na enige onrust gaat het medicijn de patiënt kalmeren. after some clamor goes the medicine the patient calm 'After some clamor, the medicine will calm the patient.' 


\section{Fillers with context}

Dit gaat over een romantisch gebaar dat regelrecht uit een film lijkt te komen. Er is een belangrijke bestelling gedaan bij de bloemist. Wat gaat er gebeuren op Valentijnsdag?

'This is about a romantic gesture that seems to come straight from a movie. An important order was placed at the florist's. What will happen on Valentine's day?'

Intended answer: Op Valentijnsdag gaat het boeket de secretaresse verrassen. on Valentine's-day goes the bouquet the secretary surprise

'On Valentine's day, the bouquet will surprise the secretary.'

Dit gaat over Tara die het leuk vindt om te luisteren. Haar lievelingsboek is 'Rupsje Nooitgenoeg'. Wat gaat er gebeuren?

'This is about Tara, who likes listening. Her favorite book is 'The Very Hungry Caterpillar.' What will happen?'

Intended answer: De babysitter gaat de kleuter het verhaal voorlezen.

the babysitter goes the toddler the story read

'The babysitter will read the toddler the story.'

Recall that each target sentence in the T/F set is used across three conditions, and each target sentence in the PA set is used across two conditions. To ensure that participants would not see the same sentence twice and would receive an equal number of items per condition, the items were distributed across six experimental lists according to a Latin Square. Each experimental list contains eight items in the anaphoric topic condition, eight items in the anaphoric focus condition, and eight items in the non-anaphoric focus condition from the T/F item set, as well as four items with context and four items without context from the PA item set. Each list also contains all 48 filler items, adding up to a total of 80 trials per list. The experiment was designed and administered using the free software program OpenSesame v3.2.5 (Python v2.7.13).

\subsection{Procedure}

Participants are seated in a sound-proof lab where the experiment takes place on a computer. The experimenter is in a separate room during the experiment where they monitor the computer screen and ensures that the participant properly executes the task. The experiment starts with a written introduction on a black screen, as illustrated in (27), ${ }^{8}$ and three practice trials, after which participants have the opportunity to ask questions. The introduction and practice trials are initiated by the experimenter.

\footnotetext{
${ }^{8} \mathrm{We}$ cropped and inverted the colors of background and text in (27), (28), and (29) to make the paper more print-friendly. 


Wat gaat er gebeuren?
In dit experiment wordt telkens de vraag gesteld "wat gaat er gebeuren?".
Hierna wordt het begin van een zin getoond. Aan jou de taak om deze
zinnen af te maken met de woorden op het scherm. Het is de bedoeling
dat je de volledige zin luid en duidelijk uitspreekt. Maak de zin vast af in je
hoofd voordat je hem uitspreekt, maar probeer wel zo snel mogelijk
antwoord te geven. De woorden verdwijnen van het scherm zodra je
begint te spreken.
De meeste zinnen worden voorafgegaan door een kort verhaaltje. Het is de
bedoeling dat je ook deze zinnen voorleest. Het experiment gaat pas door
naar het volgende scherm als je op een knop drukt, dus je hebt alle tijd
om de verhaaltjes rustig voor te lezen.
Eerst volgen er een aantal oefenzinnen, daarna heb je de gelegenheid om
vragen te stellen aan de experimentleider. Bij het echte experiment zijn
tevens een aantal pauzes ingebouwd.
Alvast heel erg bedankt voor je hulp!

\section{Translation of the instructions:}

'In this experiment you will be asked the question "what will happen?". Next, the beginning of a sentence is displayed. It is up to you to complete these sentences using the words on the screen. You are meant to speak out the full sentence, loudly and clearly. Complete the sentence in your head before articulating it, but try to answer as quickly as possible. The words will disappear from the screen the moment you start speaking.'

'Most sentences are preceded by a short story. You are meant to read these sentences out loud as well. The experiment only continues to the next screen when you push a button, so you can take your time to read out the stories at your ease.'

'First, a few practice sentences follow; after that, you can ask questions to the experiment leader. Moreover, there are built-in breaks in the real experiment.'

'Thank you very much for your help!'

The experimental trials are presented in randomized order and are presented as follows. The preamble of an experimental item is presented as written text on a black screen. Participants read these at their own pace but are instructed to read them out loud to fully indulge them in the story. An example is given in (28). A button press takes the participant to the next screen. The prompt of the target sentence is projected in written form on this second black screen, followed by three constituents listed vertically, see (29). Participants are asked to complete the target sentence orally using these three constituents. Participants' responses are recorded on a separate audio recording device for later transcription. 


Dit gaat over een geleende fiets die Sophie heeft
gesloopt. Het is een zwarte fiets met een flinke slag in
het wiel. Wat gaat er gebeuren met de fiets?
Druk op een toets om door te gaan.

\section{Translation of preamble:}

'This is about a borrowed bicycle that Sophie wrecked. It is a black bicycle that has a buckled wheel. What will happen with the bicycle?'

'Press a button to continue.'

\begin{tabular}{|} 
Sophie gaat \\
repareren \\
de fiets \\
gauw
\end{tabular}

\section{Translation of prompt and constituents:}

Sophie goes - repair - the bicycle - soon

The order of the three constituents to be used in the participant response (verb, object, adverb) is randomized throughout the experiment, but the relative order of adverb and object is equally distributed and logged in an output file, so that the presentation order can be included in our statistical analyses as a separate factor. This way, we can control for putative priming effects, as participants may be inclined to follow the order of constituents on the screen when producing the target sentence, which could possibly overrule the underlying competence that we intend to test. Furthermore, we ensured that the constituents are not projected on the computer screen at the moment that the participant is articulating their response; a voice key causes the screen with the constituents to be replaced by a screen with a fixation dot at voice onset. The constituent screen has a built-in six-second timer to reduce the number of late responses. This enhances the naturalness of the response, which hopefully represents implicit knowledge and excludes the application of potential explicit knowledge, which usually takes more time. The screen with the fixation dot has a built-in four-second timer before the next experimental trial is presented. Four seconds turned out to be enough time to fully pronounce the short target sentences in almost all trials. The experiment includes three breaks: one after every twenty trials.

\subsection{Analysis}

A total of 1344 trials (32 target sentences * 42 participants) were transcribed verbatim by the experimenter and annotated for word order (scrambled or unscrambled). 27 responses $(2.75 \%)$ were labeled 'irrelevant', because they did not contain material relevant to scrambling (i.e. a missing adverb or object), because the object had 
Table 7 Placement of definite objects per condition in the $\mathrm{T} / \mathrm{F}$ item set

\begin{tabular}{llll}
\hline & Scrambled & Unscrambled & $p$ \\
\hline Anaphoric topic & $57 \%(188 / 332)$ & $43 \%(144 / 332)$ & $.009 *$ \\
Anaphoric focus & $42 \%(138 / 332)$ & $58 \%(194 / 332)$ & $.002 *$ \\
Non-anaphoric focus & $35 \%(110 / 319)$ & $66 \%(209 / 319)$ & $<.001^{*}$ \\
\hline
\end{tabular}

an indefinite article, or because the participant skipped the trial by accident. These responses were discarded from the data prior to statistical analysis. To test whether definite objects within each condition occurred in scrambled or unscrambled position more often than could be expected on the basis of chance, we first compared the observed distributions of object placement in a series of binomial tests. If scrambling of definite objects is truly optional, the observed proportions should not differ from those in a uniform distribution. Next, we tested the observed proportions to those predicted by de Hoop (2000, 2003). Recall that de Hoop predicts that anaphoric definites occur in scrambled position in $2 / 3$ of trials and non-anaphoric definites in $1 / 2$ of trials. Additional statistical analysis of the data was then performed in two generalized mixed effects models, in which we entered condition/context and order of presentation as fixed variables to predict the position of the object, using the software $\mathrm{R}$ (v3.4.3) and the package lme4 (Bates et al. 2015). We report the results of T/F item set in Sect. 4.1, and the results of the PA item set in Sect. 4.2.

\section{Results}

\subsection{Anaphoric topics and (non-)anaphoric foci (T/F item set)}

The T/F item set contained experimental items in the anaphoric topic, anaphoric focus, and non-anaphoric focus conditions. The proportions of scrambled and unscrambled definite objects in these three conditions are presented in Table 7. This table takes responses from the two relevant orders of presentation together (ADV > OBJ and $\mathrm{OBJ}>\mathrm{ADV}$ ), as this factor did not influence object placement in a significant manner (we turn to the statistics below).

We conducted a series of binomial tests to test whether the observed proportions of scrambled utterances per condition differ significantly from what could be expected on the basis of chance. This difference reached significance in all conditions (see Table 7). These findings indicate that there is reason to assume that scrambling is not truly optional (defined as 50\% scrambled, 50\% unscrambled) for any of the definite object types tested. We then ran two more binomial test for the anaphoric topic condition and the anaphoric foci condition with the probability set to $2 / 3$, which is the proportion predicted by de Hoop $(2000,2003)$ for anaphoric definites. This yielded a significant difference in both cases $(p<0.001)$, indicating that anaphoric definites were scrambled significantly less often than $2 / 3^{\text {rd }}$ (or 66.67\%) of the time.

Next, we entered the independent variables discourse status (anaphoric topic; anaphoric focus; non-anaphoric focus) and order of presentation (ADV > OBJ; OBJ > ADV) into a generalized linear mixed effects model to predict object position (scrambled; unscrambled). The variable discourse status was encoded using two custom 
Table 8 Placement of definite objects per condition in PA set

\begin{tabular}{llll}
\hline & Scrambled & Unscrambled & $p$ \\
\hline with context & $26 \%(43 / 164)$ & $74 \%(121 / 164)$ & $<.001^{*}$ \\
without context & $21 \%(34 / 160)$ & $79 \%(126 / 160)$ & $<.001^{*}$ \\
\hline
\end{tabular}

contrasts of $(-0.5,-0.5,1)$ and $(0.5,-0.5,0)$. This allows us to separately analyze effects of anaphoricity and topicality, respectively. The first contrast is between the two anaphoric conditions (anaphoric topics and anaphoric foci) and the single non-anaphoric condition (non-anaphoric foci). We excluded the non-anaphoric focus condition in the second contrast to test for a distinct effect of topicality, which compares the scrambling pattern of anaphoric topics to that of anaphoric foci. The variable order of presentation was encoded using deviation contrasts $(0.5,-0.5)$. The initial model contained the maximal random structure, but this led to singularity. We simplified the random structure by stepwise removal of the smallest variance component. The final random structure contained by-participant and by-item varying intercepts, as well as by-participant varying slopes for discourse status and order of presentation.

We did not find a significant main effect of presentation order $(\beta=-.18$, SE $=.18, \mathrm{z}=-1.01, p=.313$ ), which indicates that sentences produced by participants were not structurally primed by the order of presentation of constituents on the computer screen. The two custom contrasts did reach significance, which indicates that anaphoric objects (anaphoric topics and anaphoric foci together) occurred in scrambled position more often than non-anaphoric foci $(\beta=-.54, \mathrm{SE}=.13, \mathrm{z}=-4.07$, $p<.001)$, and that anaphoric topics occurred in scrambled position more often than anaphoric foci $(\beta=-.40, \mathrm{SE}=.10, \mathrm{z}=-4.02, p<.001)$. The interactions between order of presentation and the two contrasts did not reach significance (anaphoricity contrast: $\beta=-.21, \mathrm{SE}=.24, \mathrm{z}=-.87, p=.384$; topicality contrast: $\beta=-.01$, $\mathrm{SE}=.20, \mathrm{z}=-.05, p=.961)$.

\subsection{Permanently available topics (P/A item set)}

The PA item set contained experimental items with a permanently available topic in a condition with context and a condition without context. The results are presented in Table 8. Note that the target objects in the two conditions were invariably nonanaphoric topics. The two presentation orders are once again taken together in Table 8 , because this factor did not influence the results in this item set either (as the statistical results below demonstrate).

The observed distribution of object placement in the data differs significantly from a uniform distribution in both the condition with context and the condition without context $(p<.001$; see Table 8$)$. The observed proportions of scrambled objects in this item set are significantly below chance level.

We then entered the independent variables context (with context; without context) and order of presentation (ADV > OBJ; OBJ $>$ ADV) into a generalized linear mixed effects model to predict the object position (scrambled; unscrambled). Both independent variables were coded using deviation contrasts $(0.5,-0.5)$. The initial model contained the maximal random structure, but this led to singularity. We simplified 
the random structure by stepwise removal of the smallest variance component. The final random structure consisted of by-participant and by-item intercepts and varying slopes for order of presentation.

The model yielded no significant main effects of context $(\beta=.60, \mathrm{SE}=.36, \mathrm{z}$ $=1.65, p=.099)$ nor order of presentation $(\beta=-.17, \mathrm{SE}=.56, \mathrm{z}=-.31, p=$ .759). The interaction effect between these factors failed to reach significance $(\beta=$ $-.19, \mathrm{SE}=.75, \mathrm{z}=-.25, p=.801)$. Permanently available topics were produced in unscrambled position more often than could be expected on the basis of chance, but we found no evidence that this preference was influenced by the presence of context or by the order of presentation of the constituents.

\section{Discussion}

Existing theories in linguistic literature present a variety of predictions regarding the scrambling behavior in language production of different types of definite direct objects. Our experiment empirically tested these predictions (see Table 5). We also posed the question whether scrambling is obligatory or optional.

Let us first consider the effect of anaphoricity, which in our experiment was a contrast between one the one hand anaphoric topics and foci, and on the other hand nonanaphoric foci. Neeleman and Reinhart (1998) predict that anaphoric topics scramble obligatorily and that non-anaphoric foci obligatorily remain unscrambled. ${ }^{9}$ Schaeffer $(1997,2000)$ claims that definite objects must appear in scrambled position if they are anaphoric, and in unscrambled position if they are not. Recall, however, that neither Neeleman and Reinhart nor Schaeffer are concerned with anaphoric foci in their analyses. Similar to Schaeffer $(1997,2000)$, de Hoop (2000, 2003) predicts that anaphoric objects scramble more often than non-anaphoric objects. Van Bergen and de Swart (2009) and de Swart and van Bergen (2011) predict no substantial proportions of anaphoric objects in scrambled position. Our results show that anaphoric objects (topics and foci taken together) were produced in scrambled position more frequently than non-anaphoric objects (or, non-anaphoric foci). Thus, our data generally corroborate the analyses in Neeleman and Reinhart (1998), Schaeffer (1997, 2000), and de Hoop (2000, 2003), and do not replicate the findings of van Bergen and de Swart (2009) and de Swart and van Bergen (2011). However, while our data suggest that even though scrambling of anaphoric objects is not truly optional (defined as a 50-50 distribution), they also indicate that it is by no means an obligatory operation: about half of the anaphoric objects (topics and foci) remained unscrambled, contra Neeleman and Reinhart (1998) and Schaeffer (1997, 2000). And while de Hoop's $(2000,2003)$ account accommodates a certain degree of freedom, it predicts that anaphoric objects scramble in about two out of three instances. This prediction is not borne out; the proportions of anaphoric definites in scrambled position in our data are much lower. None of the accounts that pertain to the anaphoricity of the

\footnotetext{
${ }^{9}$ The predictions from Neeleman and Reinhart (1998) actually pertain to the object's accessibility (Ariel 1990) or D-linkedness (Pesetsky 1987), rather than its anaphoricity alone, but since Neeleman and Reinhart do not explicitly discuss non-anaphoric foci, it makes sense to discuss their predictions in this paragraph.
} 
direct object thus seem to make exactly the right predictions, although we did find evidence for the claim that anaphoric objects scramble more often than non-anaphoric objects.

The discrepancy between our data and the data in de Swart and van Bergen's (2011) is rather striking, since the experiments were very similar in design. However, recall that de Swart and van Bergen note that the non-anaphoric objects in their experiment were still salient in discourse because, despite not having been mentioned explicitly, the foregoing context did mentally activate them (see Sect. 2.6). The discourse salience of their non-anaphoric objects possibly undermined the experimental manipulation, and the question arises whether the objects could have been sufficiently activated to render the labeling non-anaphoric as disputable. Our experiment dealt with this confounding factor by eliminating a linguistic context altogether in the nonanaphoric focus condition.

An alternative explanation for the discrepancy between de Swart and van Bergen's (2011) results and ours was suggested to us by Peter de Swart (p.c.), who noticed that participants in their experiment were faced with time pressure, while ours were not. The prompt of the target sentence in de Swart and van Bergen's experiment (consisting of an adverbial expression and the auxiliary heeft 'has') was presented on a first screen, which remained visible until a participant started speaking. The constituents for completion then appeared on a second screen after 1500 milliseconds. In our experiment, the constituents for completion were presented on the same screen as the prompt (consisting of a proper name and the auxiliary heeft 'has'). The prompt and the constituents for completion both remained visible until the moment a participant started speaking (or until a six-second timer ran out). The crucial difference is that our design allowed participants to construct a full sentence before voice onset, whereas de Swart and van Bergen's design did not. It is conceivable that participants who are pressurized into responding as quickly as possible have a preference for the unscrambled order, such as the one reported by de Swart and van Bergen, on the assumption that the unscrambled order is also the syntactically unmarked order (as claimed by e.g. Neeleman and van de Koot 2008).

A possible reason for the discrepancy between our experimental data and the corpus data in van Bergen and de Swart (2009) is that we only tested for direct objects that were preceded by a definite article in clauses with a temporal adverb. The category of definite objects in van Bergen and de Swart's study, by contrast, also contains constructions with a demonstrative pronoun (e.g. die man 'that man'), a possessive pronoun (e.g. zijn moeder 'his mother'), and a definite quantifier (e.g. alle vragen 'all questions'). Once the corpus data are filtered for items with direct objects preceded by a (referential) definite article, only 107 items remain, as opposed to the 1317 items in our experimental dataset. Van Bergen and de Swart note that speakers are more likely to use pronouns instead of noun phrases when the referent has been mentioned in the discourse, which explains the relatively low number of anaphoric noun phrases in their data. Participants in our experiment were forced to use a noun phrase. Further, the 107 items in van Bergen and de Swart's dataset contain scrambling clauses with many different types of adverbs, including the negation word niet 'not' and the affirmative particle wel. It has been shown before that scrambling preferences in language production differ drastically depending on whether the clause contains a 
temporal adverb or negation, that is, the preference for definite objects to be located in scrambled position is much stronger in clauses with negation than in clauses with a temporal adverb (Schoenmakers and de Swart 2019). As such, van Bergen and de Swart's dataset is both smaller and more heterogeneous than ours, which makes it difficult to compare the two.

Finally, since we did not provide a linguistic context in the non-anaphoric focus condition, the effect that we found between the anaphoric and non-anaphoric conditions can be interpreted in two ways: either it is a genuine effect of anaphoricity, or it is an effect due to the presence of linguistic context. To disentangle these two factors, we manipulated the presence of a linguistic context between the two conditions in the PA item set: one with a preamble, and one without. The presence of linguistic context was the only factor differentiating the items in this item set, as the objects in the two conditions were both non-anaphoric and permanently available topics. Our statistical analyses do not provide evidence for a difference between the results of these conditions. We conclude that the presence of linguistic context did not influence the scrambling behavior of definite objects in the PA item set, and by analogy, that the effect in the T/F item set (that anaphoric objects were scrambled more often than non-anaphoric objects) is a genuine effect of anaphoricity (contra van Bergen and de Swart 2009; de Swart and van Bergen 2011).

Let us now turn to the effect of topicality. It is important to keep in mind that the topics and foci in conditions A and B of our experiment (see the examples in (21)) were always anaphoric, that is, we kept the anaphoricity of the objects constant to examine the effect uniquely due to their topicality. Erteschik-Shir (2007) agrees with Schaeffer $(1997,2000)$ that such objects must scramble by virtue of their anaphoricity, but she makes a distinction between continuous and shifted topics. Her analysis predicts specifically that only continuous topics scramble; shifted topics and foci are predicted to appear in unscrambled position. While, strictly speaking, we did not investigate shifted topics in our experiment, one could argue that our anaphoric foci may alternatively be analyzed as shifted topics in the sense of Erteschik-Shir, on the assumption that the activation of the object's discourse referent extends over the short middle sentence in the preamble (see fn. 7). In this case, our results provide some support for Erteschik-Shir's predictions: continuous topics (our anaphoric topics) occur in scrambled position more often than shifted topics (our anaphoric foci), and therefore, continuous and shifted topics engage in scrambling in different ways. However, it is unclear how long the activation status of a newly introduced referent extends in discourse, but note that the alternative interpretation of this condition does not affect Erteschik-Shir's predictions: shifted topics and anaphoric foci are both predicted to appear on the right side of temporal adverbs.

To summarize the effect of topicality on definite object scrambling, then, our results indicate that (anaphoric) topics were scrambled more frequently than (anaphoric) foci (pace Neeleman and Reinhart 1998). We repeat that the anaphoric topics in our experiment were not scrambled categorically; rather, the observed distributions indicate a high degree of freedom in placement. The data therefore do not corroborate the claim in Erteschik-Shir (2007) that (continuous) topics scramble obligatorily.

With regard to the permanently available topics, Schaeffer $(1997,2000)$ and Erteschik-Shir (2007) suggest that non-anaphoric objects do not scramble, regard- 
less of their topicality. The permanently available topics in our experiment had not yet been mentioned in the discourse and therefore, Schaeffer's and Erteschik-Shir's analyses predict that these objects must remain in unscrambled position. By contrast, de Hoop $(2000,2003)$ predicts that non-anaphoric definite objects (including permanently available topics) scramble half of the time. The results from our experiment show that non-anaphoric permanently available topics were produced in scrambled position in about one out of four trials. These proportions were lower than could be expected on the basis of chance, that is, there was a clear preference to keep non-anaphoric permanently available topics in unscrambled position (contra de Hoop 2000, 2003). But such topics are not obligatorily located in this position either (contra Schaeffer 1997, 2000; Erteschik-Shir 2007).

Regarding the question of whether or not scrambling is an obligatory operation, we observe the following. We already mentioned that while the proportion of scrambled anaphoric topics is significantly different from a chance-level distribution, they do not always occur in scrambled position (only in $57 \%$ of the trials). This finding goes against the claims in Neeleman and Reinhart (1998), Schaeffer (1997, 2000), and Erteschik-Shir (2007), that scrambling is obligatory for anaphoric and/or topical objects. In addition, the results from our T/F item set show that while anaphoric foci occur in unscrambled position significantly less often than could be expected on the basis of chance, they do not always occur in unscrambled position either (only in $58 \%$ of the trials). These two findings do not corroborate the claim in van Bergen and de Swart (2009) and de Swart and van Bergen (2011) that anaphoric objects hardly scramble at all. ${ }^{10}$ De Hoop's $(2000 ; 2003)$ analysis is different in that it involves a certain degree of freedom for anaphoric definites, specifically, they are predicted to occur in scrambled position in roughly two out of three trials. We did not find evidence for this prediction; rather, the observed proportions of scrambled objects were much lower for both anaphoric topics and anaphoric foci. Finally, all of the analyses discussed in this paper would predict non-anaphoric foci, if anything, to occur in unscrambled position in the vast majority of cases (except for de Hoop's 2000, 2003 analysis, which instead predicts a 50-50 distribution). Our results indicate that non-anaphoric foci occur in unscrambled position more often than could be expected on the basis of chance, but still they only do so in about two out of every three trials. This finding was not predicted by any of the scrambling accounts. However, note that all of our non-anaphoric focus objects were definite noun phrases, which might imply commonly shared knowledge between speaker and hearer (i.e. topicality). This may have influenced the results.

Everything considered, we conclude that:

i) scrambling is not obligatory for any type of definite object;

ii) non-anaphoric permanently available topics are preferred in unscrambled position;

\footnotetext{
${ }^{10}$ Again, under an alternative information structural partitioning (see fn. 7), this latter finding can also be taken as evidence against Erteschik-Shir's (2007) claim that shifted topics do not scramble over temporal adverbs at all. It can also be considered evidence against Schaeffer's $(1997,2000)$ claim that scrambling is obligatorily regulated by anaphoricity, however, she does not explicitly discuss anaphoric foci in her analysis.
} 
Table 9 Proportions of scrambled objects per object type in our dataset

\begin{tabular}{ll}
\hline Definite object type & Proportion scrambling \\
\hline Anaphoric topic & $57 \%$ \\
Anaphoric focus & $42 \%$ \\
Non-anaphoric focus & $35 \%$ \\
Permanently available topic & $24 \%$ \\
\hline
\end{tabular}

iii) anaphoric objects are produced in scrambled position more often than nonanaphoric objects;

iv) (anaphoric) topics are produced in scrambled position more often than (anaphoric) foci.

The proportions of scrambled objects that we found in our dataset are repeated for each type of definite object in Table 9 . The proportion for the permanently available topics is an average of the conditions with and without context. The proportions of scrambled definites show a pattern that seems to follow a principle known as the Given-before-New Principle in (30), taken from Gundel (1988), ${ }^{11}$ in that anaphoric (given) definite objects occur in the earlier scrambled position more often than nonanaphoric (new) definite objects.

\section{Given-before-New Principle}

State what is given before what is new in relating to it. (Gundel 1988:229)

Moreover, we concluded on the basis of data from the T/F item set that topics are more likely to appear in scrambled position than foci. It is therefore quite surprising to find that the category of permanently available topics shows the lowest proportion of scrambled items in our dataset-the observed proportion of scrambled permanently available topics is even lower than non-anaphoric foci. It has been reported before that the distribution of permanently available topics cross-linguistically is not as predictable as that of other definites, and that permanently available topics often constitute exceptions to more general rules (Givón 1983: 10). We thus conclude that while the topicality and the anaphoricity of a definite object both influence its likeliness to scramble, its anaphoricity seems a more rigid predictor (contra Neeleman and Reinhart 1998; van Bergen and de Swart 2009; de Swart and van Bergen 2011; but in line with Schaeffer 1997, 2000; de Hoop 2000, 2003). We argue that each type of definite object engages in Dutch direct object scrambling in its own specific way and that a definite object's topicality or anaphoricity alone does not explain the full variance in scrambling constructions with a temporal adverb.

Based on our data we conclude that scrambling is never obligatory (as even anaphoric topics were scrambled in only just over half of the trials). However, despite the relatively large degree of freedom that our data seem to display with respect to it, scrambling is not truly optional either. Scrambling is affected by the anaphoricity of the object, following the principle in (30), and by the topicality of the object. Regarding the existing scrambling theories, this means the following.

\footnotetext{
${ }^{11}$ Traditional grammarians were already aware of this principle (e.g. Weil 1844; Behaghel 1909). Here, we chose to represent the observation using Gundel's (1988) definition.
} 
Neeleman and Reinhart (1998) do not make the information structural distinctions within the set of definite objects needed to account for the observed scrambling data (specifically, they do not address the scrambling behavior of non-anaphoric topics and of anaphoric foci). They propose that topics scramble more often than foci, but are too rigorous in their claims regarding the obligatoriness of scrambling. Schaeffer (1997, 2000) makes a distinction between anaphoric and non-anaphoric definite objects, and claims that scrambling is obligatory for the former type and prohibited for the latter type. This means she is too rigorous in her claims regarding the obligatoriness of scrambling as well. Erteschik-Shir (2007) proposes that only continuous topics scramble, and that they scramble obligatorily, whereas shifted topics and foci must remain unscrambled. Although at this point it is not entirely clear whether our experiment tested shifted topics or anaphoric foci, Erteschik-Shir's analysis predicts that neither of them scrambles at all. This indicates that she is too rigorous in her claims regarding the obligatoriness of scrambling. In contrast, de Hoop (2000, 2003) makes a distinction between anaphoric and non-anaphoric definites, and argues that scrambling is never obligatory for either category. Her analysis predicts that twothirds $(67 \%)$ of anaphoric objects and half of non-anaphoric objects $(50 \%)$ appear in scrambled position. These predictions are too strong; the proportions observed in our data are lower: $42-57 \%$ for anaphoric objects and $21-34 \%$ for non-anaphoric objects (across all conditions). Nevertheless, the scrambling proportions reported in the current study corroborate de Hoop's claims that scrambling is not obligatory, supporting her earlier claim that "[...] there does not seem to be a property of either the definite itself or the context in general that forces or prohibits scrambling" (van der Does and de Hoop 1998: 399; emphasis ours), and they also corroborate her claim that anaphoric objects appear in scrambled position more often than non-anaphoric objects. Finally, van Bergen and de Swart (2009) and de Swart and van Bergen (2011) do not find evidence for an effect of anaphoricity in their corpus and experimental data, nor any substantial proportions of scrambled definites. We did not replicate these findings in our study; instead, we found that the anaphoricity of an object influences its likeliness to be produced in scrambled position, and we report substantial scrambling proportions (see Table 9 above).

We believe our results best corroborate de Hoop's (2000, 2003) account, who claims that scrambling of definite objects is not obligatory but influenced by their anaphoricity. Yet, the proportions of scrambled definites are much lower than her analysis predicts (in line with van Bergen and de Swart 2009; de Swart and van Bergen 2011). Everything considered, our data indicate that the discourse status of the definite direct object in and of itself cannot explain the full scrambling variation, but that scrambling is affected by anaphoricity and topicality of the direct object.

\section{Conclusion}

The present study investigated the scrambling behavior of different types of definite direct objects in Dutch: anaphoric topics, anaphoric foci, non-anaphoric foci, and (non-anaphoric) permanently available topics. The results do not fully corroborate any of the existing analyses on Dutch definite direct object scrambling, but they do 
provide evidence for the assumption that scrambling of definite objects is influenced by their topicality and anaphoricity. Specifically, anaphoric topics scramble most often, followed by anaphoric foci, followed by non-anaphoric foci, and finally followed by (non-anaphoric) permanently available topics. Since none of the scrambling proportions in our data are close to either $0 \%$ or $100 \%$, we conclude that scrambling is not obligatory for any type of definite. But the distribution of definites in the Dutch middle-field is not completely free either; rather, scrambling is a process that is not determined, but is influenced by discourse conditions, in that the topicality and the anaphoricity of a definite direct object affect its likeliness to be produced in scrambled position.

Acknowledgements We are grateful to three anonymous reviewers whose feedback helped improve the paper. We would also like to thank Helen de Hoop, Peter de Swart, and the Grammar and Cognition research group at University of Amsterdam for their comments on earlier versions of the paper.

Open Access This article is licensed under a Creative Commons Attribution 4.0 International License, which permits use, sharing, adaptation, distribution and reproduction in any medium or format, as long as you give appropriate credit to the original author(s) and the source, provide a link to the Creative Commons licence, and indicate if changes were made. The images or other third party material in this article are included in the article's Creative Commons licence, unless indicated otherwise in a credit line to the material. If material is not included in the article's Creative Commons licence and your intended use is not permitted by statutory regulation or exceeds the permitted use, you will need to obtain permission directly from the copyright holder. To view a copy of this licence, visit http://creativecommons.org/licenses/by/ $4.0 \%$.

\section{References}

Anttila, Arto, and Young-mee Yu Cho. 1998. Variation and change in optimality theory. Lingua 104: 31-56.

Ariel, Mira. 1990. Accessing noun-phrase antecedents. London: Routledge.

Asher, Nicholas, and Alex Lascarides. Bridging 1998. Journal of Semantics 15(1): 83-113.

Bates, Douglas, Martin Mächler, Benjamin Bolker, and Steven Walker. 2015. Fitting linear mixed-effects models using lme4. Journal of Statistical Software 67(1): 1-48.

Beaver, David, and Brady Clark. 2008. Sense and sensitivity: How focus determines meaning. Oxford: Blackwell Sci.

Behaghel, Otto. 1909. Beziehungen zwischen Umfang und Reihenfolge von Satzgliedern. Indogermanische Forsuchingen 25: 110-142.

van Bergen, Geertje, and Peter de Swart. 2009. Definiteness and scrambling in Dutch: Where theory meets practice. In North East Linguistic Society (NELS), eds. Anisa Schardl, Martin Walkow, and Muhammad Abdurrahman. Vol. 38, 89-100. Amherst: GLSA.

Broekhuis, Hans. 2008. Derivations and evaluations: Object shift in the Germanic languages. Berlin: de Gruyter Mouton.

Büring, Daniel. 2016. Intonation and meaning. Oxford: Oxford University Press.

Chafe, Wallace. 1976. Givenness, contrastiveness, definiteness, subjects, topics and points of view. In Subject and topic, ed. Charles Li, 25-55. New York: Academic Press.

Choi, Hye-Won. 1996. Optimizing structure in context: Scrambling and information structure. PhD diss., Stanford University

Cinque, Guglielmo. 1993. A null theory of phrase and compound stress. Linguistic Inquiry 24(2): 239-298.

Cinque, Guglielmo. 1999. Adverbs and functional heads: A cross-linguistic perspective. Oxford: Oxford University Press.

Clark, Herbert. 1975. Bridging. In Proceedings of theoretical issues in natural language processing, eds. Roger Schank and Bonnie Nash-Webber, 169-174. Cambridge: MIT. 
van der Does, Jaap, and Helen de Hoop. 1998. Type-shifting and scrambled definites. Journal of Semantics 15(4): 393-416.

Erteschik-Shir, Nomi. 1997. The dynamics of focus structure. Cambridge: Cambridge University Press.

Erteschik-Shir, Nomi. 2007. Information structure: The syntax-discourse interface. Oxford: Oxford University Press.

Givón, Talmy. 1983. Topic continuity in discourse: A quantitative cross-language study. Amsterdam: Benjamins.

Gundel, Jeanette. 1988. Universals of topic-comment structure. In Studies in syntactic typology, eds. Michael Hammond, Edith Moravczik, and Jessica Wirth, 209-239. Amsterdam: Benjamins.

de Hoop, Helen. 2000. Optional scrambling and interpretation. In Interface strategies, eds. Hans Bennis and Martin Everaert, 153-168. Amsterdam: Holland Academic Graphics.

de Hoop, Helen. 2003. Scrambling in Dutch: Optionality and optimality. In Word order and scrambling, ed. Simin Karimi, 201-216. Malden: Blackwell Sci.

Jackendoff, Ray. 1972. Semantic interpretation in generative grammar. Cambridge: MIT Press.

Lambrecht, Knud. 1994. Information structure and sentence form. Cambridge: Cambridge University Press.

Marslen-Wilson, William, Elena Levy, and Lorraine Komisarjevsky Tyler. 1982. Producing interpretable discourse: The establishment and maintenance of reference. In Speech, place and action: Studies in deixis and related topics, eds. Robert Jarvella and Wolfgang Klein, 339-378. Chichester: Wiley.

Neeleman, Ad. 1994. Scrambling as a D-structure phenomenon. In Studies on scrambling: Movement and non-movement approaches to free word-order phenomena, eds. Norbert Corver and Henk van Riemsdijk, 387-430. Berlin: de Gruyter Mouton.

Neeleman, Ad, and Tanya Reinhart. 1998. Scrambling and the PF interface. In The projection of arguments, ed. Miriam Butt, and Wilhem Geuder, 309-353. Stanford: CSLI Publications.

Neeleman, Ad, and Hans, van de Koot. 2008. Dutch scrambling and the nature of discourse templates. Journal of Comparative Germanic Linguistics 11(2): 137-189.

Pesetsky, David. 1987. Wh-in-situ; movement and unselective binding. In The representation of (in)definites, eds. Eric Reuland, and Alice ter Meulen, 98-129. Cambridge: MIT Press.

Reinhart, Tanya. 1981. Pragmatics and linguistics: An analysis of sentence topics. Philosophica 27: 53-94.

Ross, John. 1967. Constraints on variables in syntax. PhD diss., MIT.

Schaeffer, Jeannette. 1997. Direct object scrambling in Dutch and Italian child language. PhD diss., University of California, Los Angeles.

Schaeffer, Jeannette. 2000. The acquisition of direct object scrambling and clitic placement: Syntax and pragmatics. Amsterdam: Benjamins.

Schoenmakers, Gert-Jan, and Peter de Swart. 2019. Adverbial hurdles in Dutch scrambling. In Proceedings of linguistic evidence 2018: Experimental data drives linguistic theory, eds. Anja Gattnar, Robin Hörnig, Melanie Störzer, and Sam Featherston, 124-145. Tübingen: University of Tübingen.

Schoenmakers, Gert-Jan. 2020. Freedom in the Dutch middle-field: Deriving discourse structure at the syntax-pragmatics interface. Glossa: A Journal of General Linguistics 5(1): 1-22. 114.

Sgall, Petr, Eva Hajičová, and Jarmila Panevová. 1986. The meaning of the sentence in its semantic and pragmatic aspects. Dordrecht: Reidel.

de Swart, Henriëtte, and Helen de Hoop. 2000. Topic and focus. In The first glot international state-ofthe-article book: The latest in linguistics, ed. Lisa Cheng, and Rint Sybesma, 105-130. Berlin: de Gruyter Mouton.

de Swart, Peter, and Geertje van Bergen. 2011. Definiteness and adverb-object order in Dutch. Manuscript University of Groningen and Université Catholique Louvain-La-Neuve.

Unsworth, Sharon. 2005. Child L2, adult L2, child L1: Differences and similarities: A study on the acquisition of direct object scrambling in Dutch. PhD diss., Utrecht University, Utrecht.

Vallduví, Enric. 1992. The informational component. New York: Garland.

Vallduví, Enric, and Elisabet Engdahl. 1996. The linguistic realisation of information packaging. Linguistics 34(3): 459-520.

Vogels, Jorrig, and Geertje van Bergen. 2013. Where to place inaccessible subjects in Dutch: The role of definiteness and animacy. Corpus Linguistics and Linguistic Theory 13(2): 369-398.

Vanden Wyngaerd, Guido. 1989. Object shift as an A-movement rule. In MIT working papers in linguistics 11, eds. Phil Branigan, Jill Gaulding, Miori Kubo, and Kumiko Murasugi, 256-271. Cambridge: MIT Press.

Weil, Henri, 1844. De l'ordre des mots dans les langues anciennes comparées aux langues modernes. Paris: Didier Érudition. 
Publisher's Note Springer Nature remains neutral with regard to jurisdictional claims in published maps and institutional affiliations. 